\title{
Assessing the Degree of Possessing Study Skills by the Students of Tafila Technical University from Their Perspectives
}

\author{
Atallah A. Al- Roud ${ }^{1} \&$ Ahmad Thawabiah ${ }^{2, *}$ \\ ${ }^{1}$ Department of Curricula and Instruction, Faculty of Educational Sciences, Tafila Technical University (TTU), \\ Jordan. \\ ${ }^{2}$ Department of Educational Psychology, Faculty of Educational Sciences, Tafila Technical University (TTU), Jordan \\ *Correspondence: Department of Educational Psychology, Faculty of Educational Sciences, Tafila Technical \\ University (TTU), Jordan. Tel: 962-777-758-156. E-mail: ahmadthawabieh@yahoo.com
}

Received: October 11, 2016

Accepted: October 17, $2016 \quad$ Online Published: November 24, 2016

doi:10.5430/jct.v5n2p119

URL: http://dx.doi.org/10.5430/jct.v5n2p119

\begin{abstract}
The study aimed to identify the degree of possessing study skills (SS) by the students of Tafila Technical (TTU) University from their perspectives. The population of the study consisted of 5015 students in TTU for the second semester of the academic year 2015/2016. The sample of the study was chosen randomly from the population of the study with a number of 415 male and female students. The results indicated that the degree of possessing SS by students was mid and there are statistically significant differences attributed to the variables of gender and faculty. The researchers recommend that the Ministry of Education should take into account this important subject to be adopted in the curricula at schools. The universities should also adopt this course for students from the beginning of joining a university.
\end{abstract}

Keywords: students; university; study skills

\section{Introduction and Related Work}

It is well known that the environment of a school is different than a university environment either academically or socially, in addition to other areas. Academically; the students find that the way of teaching and learning at a university is different especially in the system of courses, lectures, participation....etc. Gourlay (2009) stated that the transition to university level study can place great demands both academically and socially on learning, which has been found to be the most critical in the first year student experience.

Academically, Jordanian students face problems when joining a university. At schools, the teacher relatively applies the traditional methods in the process of teaching and he was considered as the core of the process, whereas; at universities, the process is completely different because the students have to share the instructor with the process through presenting the lectures, participating in debates....etc. This means that they have to be in known with SS that they lack at schools. Regarding to social domain, Jordanian students find the environment of a university different than school since at school there is no co-education as in university.

The SS course at universities deals with several aspects which provide students with experience to develop their academic achievement, performance, and study behavior. Robbins, Lauver, Davis, Langley, and Caristorm (2004) described SS as they are generally seen as enablers of effective study behavior.

Despite the importance of SS for students, this course is a university selective one in TTU. Learning this course could help and enable students to understand the difference between short term memory and long term memory, how to manage time of study, take notes, use learning resources, read effectively, understand the assessment strategies, write accurately and logically, and revise and recall their lessons. Alipuor (1997) stated that Statistics and experiments show that a high percentage of high school students and freshmen, not having learned to study scientifically, study their lessons aloud, just retain, and memorize the materials; however, they are not thinking of recalling and reviewing their lessons. All these components of SS course form the skeleton of the process of teaching and learning. So, instead of asking students to read, write, use the library....etc. we have to teach them how to read, write, take notes...etc, taking into account the Japanese saying (instead of giving me a fish every day, let me know 
how to catch a fish).

Seif (2001) mentioned that studying, as a mental process, has its own principles and specific conditions. Studying conditions are such issues through which one can expect to have a more useful and efficient studying by knowing and applying them. A fruitful studying depends on the two following factors: 1) the reader's interest in the material or the textbook being studied and 2) his or her skillful use of reading strategies or SS. The first factor motivates the reader to study more which in turn leads to betterment of the use of SS.

Jansen and Suhre (2010) explored that many studies have revealed the importance of SS for students' first year performance and college retention, the extent of the impact of SS preparation on students' academic achievement is less clear. His paper explores the impact of pre university SS preparation on students' first year study experiences, academic achievement and persistence. The setting for this study is a large law school in the Netherlands which attracts students from more than 100 schools for secondary education. The results showed that the perceived SS preparation concerning time management and learning skills does have a positive impact on college students' first year study behavior and academic achievement. However, the study also showed that the impact of perceived college preparation is far less important for college retention than other factors such as satisfaction about the chosen degree program and tutorial attendance. They hypothesized that Preparation for the required SS is expected to have a positive effect on students' study behavior, which ultimately is expected to result in more academic progress and less dropout. Since SS can only have an effect on academic progress, if students actually apply them, a positive relationship with study motivation is assumed. We expect student ability to have a positive effect on study progress. .

Jang and Kim (2004) concluded that, effective SS - specifically students' knowledge of appropriate study strategies and methods and the ability to manage time and other resources to meet the demands of the academic tasks - have been linked to improved academic performance applicable across different subject areas and cultural contexts, which both enhance student learning and prepares them for the workplace .

Self study activities comprise learning from textbooks, group work and small scale research of subject related problems. It is assumed that such a learning environment creates ample opportunities for students to acquire and practice the types of SS necessary to complete a higher education degree program ( Smith and Bath 2006)

Burcak Levent, and Kaan (2015) indicated in the results of their study "that there is a statistically significant difference in time planning sub-dimension and general time management and this difference is in favor of non-athlete participants". The results also indicated that "male students manage their time better than female students".

Siahi, and Maiyo (2015) mentioned that the results of their study revealed positive relationship between study habits and academic achievement They added that study habits need significant attention if we are to prove performance.

Shawana, Shaukat, Iqbal, and Sobia (2012) stated that the findings of their study showed significant relationship of time management skills, reading, and note-taking skills with academic achievement, and there were no significant relationship for other SS as compared with lower academic achievement. The results also revealed that girls were better in using SS than boys.

\section{Methodology}

\subsection{Study Problem}

Through teaching at universities, the researchers noticed that students are unable to use the basic strategies of reading, writing, note-taking etc. This attracted their attention to search in this problem and to define it through answering the following questions:

1- What is the degree of possessing SS by TTU students?

2- Are there statistically significant differences in possessing SS domains attributed to gender at level $(\alpha=0.05)$ ?

3- Are there statistically significant differences in possessing SS domains attributed to faculty at level $(\alpha=0.05)$ ?

\subsection{Significance of the Study}

The results of the study could be beneficial for either the instructors and students as well. In addition to that, the curricula designers may take into account the necessity of including SS in curricula from early stage of school.

\subsection{Design}

Descriptive research approach was adopted for this study. 


\subsection{Population}

The population of the study consisted of 5015 students in TTU for the second semester of the academic year $2015 / 2016$.

\subsection{Sample}

The sample of the study consisted of 415 students which forms $8 \%$ chosen randomly from the population of the study, by choosing the students who study this course in the second semester of the academic year 2015-2016 as table (1) shows:

Table 1. Sample of the Study

\begin{tabular}{llll}
\hline Gender & College & Total \\
& Scientific & Humanitarian & \\
\hline Male & 207 & 44 & 251 \\
Female & 94 & 70 & 164 \\
Total & 301 & 114 & 415 \\
\hline
\end{tabular}

\subsection{Instrument}

The researchers developed an instrument consisted of two parts: part one is personal demographic information, part two is the domains and the items of the questionnaire including (45) items divided into (5) domains: study management consists of (11) items, linguistic (9) items, learning resources (6) items, writing reports and researches (9) items, and tests (10) items.

\subsubsection{Validity}

The instrument was distributed to four specialists and experienced referees in curricula and assessment. The notes of the referees where taken into account and the modified copy was adopted.

\subsubsection{Reliability}

The reliability for the instrument and domains was computed by test re-test. The instrument was applied twice on a sample of (20) students out of the study sample with a duration of two weeks between the two tests. Internal consistency was computed by using Cronbach alpha equation as table (2) shows:

Table 2. Reliability of the Study

\begin{tabular}{lll}
\hline Domains & Cronbach alpha & Test- Retest \\
\hline Study management & 0.80 & 0.85 \\
Linguistic & 0.89 & 0.92 \\
Learning resources & 0.87 & 0.89 \\
Writing reports and researches & 0.81 & 0.85 \\
Tests & 0.79 & 0.82 \\
Total & 0.90 & 0.94 \\
\hline
\end{tabular}

Table (2) indicates that the reliability coefficients are acceptable for the purposes of conducting this study.

\section{Results}

For answering question (1) which runs: What is the degree of possessing SS by TTU students from their perspective? Means and standard deviations (SDs) were computed as table (3) shows: 
Table 3. Means and SD's for the Degree of Possessing SS by (TTU) Students According to Domains and Items

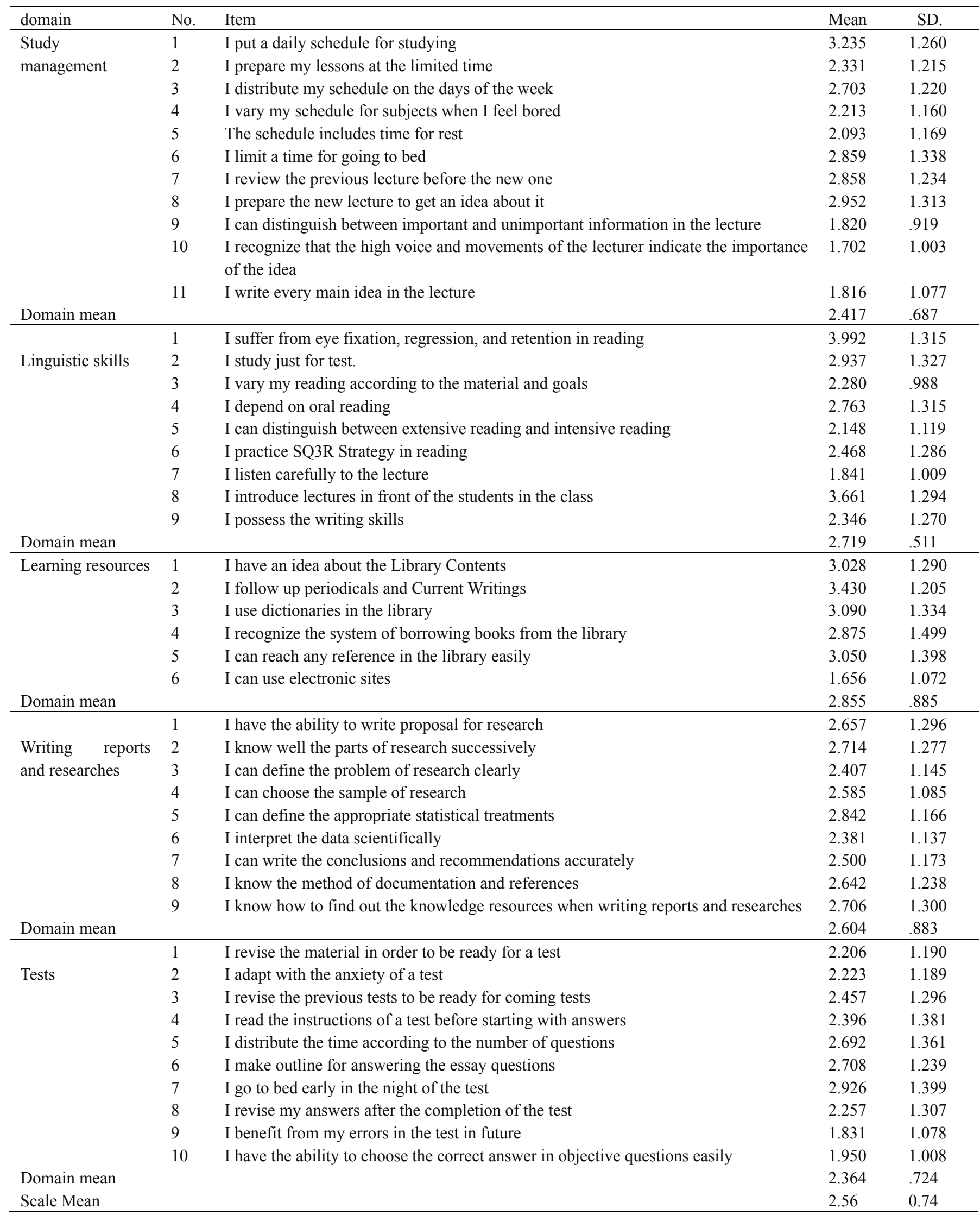


The figures indicated that the degree of possessing SS by students was medium for the entire domains with a mean of (2.56). The learning resources domain was the highest one with a mean of (2.85), followed by linguistic skills domain with a mean of (2.71), then writing reports and researches domain with a mean of (2.60) and study management domain with a mean of (2.41), and the lowest one was tests domain with a mean of (2.36).

Regarding the items of the domains, in the first domain (study management) item number one which runs, I put a daily schedule for studying, got the highest mean of (3.23) and the lowest item mean was number (10) which runs, I can recognize that the high voice of the lecturer and his movements indicate the importance of the idea with a mean of (1.70) followed by item number (11) which states, I write every main idea in the lecture, with a mean of (1.81), then item number (9) which runs, I can distinguish between important and unimportant information in the lecture with a mean of (1.82).

The second domain (linguistic skills domain) consisted of (9) items. The items of this domain came between low and high. The results indicated that item number (1) which states I suffer from eye fixation, regression and retention in reading came as the highest with a mean of (3.99), followed by item number (8) which runs I introduce lectures in front of students in the class with a mean of (3.68). The lowest item was number (7) which states I listen carefully to the lecturer with a mean of (1.84).

The third domain (learning resources domain) consisted of (6) items. The results indicated that item number (2) which runs, I follow up periodicals and current writings got the highest mean of (3.43) followed by item number (3) which runs, I use dictionaries in the library with a mean of (3.09).. The lowest item mean was for number (6) which runs I can use electronic sites with a mean of (1.65).

The fourth domain (writing reports and researches) consisted of (9) items which came between a mean of (2.842) as the highest item that runs I can define the appropriate statistical treatments and the lowest item with a mean of (2.381) which runs I interpret the data scientifically.

The fifth domain (test) consisted of (10) items that came between a mean of (2.926) for item (7) which runs, I go to bed early in the night of the test as the highest item and item (9) which runs, I benefit from my errors in the test in future as the lowest one with a mean of (1.831).

For answering question (2): Are there statistically significant differences at level $(\alpha=0.05)$ attributed to gender?. Means and SDs were computed as table (4) shows:

Table 4. Means and Standard Deviations for the Degree of Possessing SS by (TTU) Students According to Gender

\begin{tabular}{llll}
\hline Gender & Domain & Mean & Std. Deviation \\
\hline \multirow{6}{*}{ Male } & Study management & 2.5049 & 0.68729 \\
& Linguistic & 2.7588 & 0.50087 \\
& Learning resources & 2.9044 & 0.88907 \\
& Writing reports and researches & 2.6205 & 0.89776 \\
& Tests & 2.4211 & 0.71176 \\
& Grand mean & 2.6132 & 0.53156 \\
& Study management & 2.2886 & 0.66909 \\
& Linguistic & 2.6619 & 0.52319 \\
& Learning resources & 2.7838 & 0.87891 \\
& Writing reports and researches & 2.5818 & 0.86361 \\
& Tests & 2.2807 & 0.73717 \\
& Grand mean & 2.4853 & 0.53666 \\
\hline
\end{tabular}

In table (4) the means for males came between (2.90) for learning resources domain and (2.42) for test domain.

The means for females came between (2.78) for learning resources domain and (2.28) for test domain. The grand mean for the effect of gender on the degree of possessing SS by TTU students came in favor of male students in all domains with a mean of (2.61). According to the effect of gender on the degree of possessing SS by TTU students, the figures indicated that the male students possess SS in the grand mean and in all domains more than female students. 
To find out whether there are significant differences in possessing SS by TTU students attributed to gender at level $(\alpha=0.05)$ or not, Independent Sample t- test was applied as table (5) shows:

Table 5. Independent Sample t- Test for the Effect of Gender upon SSD

\begin{tabular}{lccc}
\hline \multirow{2}{*}{ Domain } & \multicolumn{3}{c}{$\mathrm{t}$-test for Equality of Means } \\
\cline { 2 - 4 } & $\mathrm{t}$ & $\mathrm{df}$ & Sig. (2-tailed) \\
\hline Study management & 3.196 & 418 & .001 \\
Linguistic & 1.910 & 418 & .057 \\
Learning resources & 1.369 & 418 & .172 \\
Writing reports and researches & 0.440 & 418 & .660 \\
Tests & 1.955 & 418 & .051 \\
Total average & 2.409 & 418 & .016 \\
\hline
\end{tabular}

In table (5), the figures indicated that there are statistically significant differences $(\alpha=0.05)$ in the total average and in study management domain in favor of male students.

For answering question (3): Are there any statistically significant differences $(\alpha=0.05)$ attributed to faculty? Means and SDs were computed as table (6) shows:

Table 6. Means and SDs for the Degree of Possessing SS by TTU According to Faculty

\begin{tabular}{llll}
\hline Domain & College & Mean & Std. Deviation \\
\hline \multirow{2}{*}{ Study management } & scientific & 2.4217 & .66777 \\
\multirow{3}{*}{ Linguistic } & humanities & 2.3972 & .74328 \\
& scientific & 2.7555 & .46758 \\
Learning resources & humanities & 2.6103 & .60600 \\
\multirow{2}{*}{ Writing reports and researches } & scientific & 2.8439 & .84848 \\
\multirow{2}{*}{ Tests } & humanities & 2.8740 & .99129 \\
& scientific & 2.5354 & .84470 \\
Grand mean & humanities & 2.7779 & .95932 \\
& scientific & 2.3664 & .67796 \\
& humanities & 2.3575 & .84862 \\
\hline
\end{tabular}

The figures in table 5 show that the means for scientific faculties came between (2.36-2.848) and standard deviations between (0.467-0.848). Regarding the faculties of humanities, the means came between (2.35-2.874) and standard deviations between (0.606-0.848). To find out whether there are significant differences in possessing SS by TTU students attributed to the faculty ( $\alpha=0.05$ ) or not, Independent Sample t-test was applied as table (7) shows:

Table 7. Independent Sample t-test for the Effect of Faculty upon SSD

\begin{tabular}{lccc}
\hline \multirow{2}{*}{ Domain } & \multicolumn{3}{c}{$\mathrm{t}$-test for Equality of Means } \\
\cline { 2 - 4 } & $\mathrm{t}$ & \multicolumn{3}{c}{$\mathrm{df}$} & Sig. (2-tailed) \\
\hline Study management & .323 & 413 & .747 \\
Linguistic & 2.594 & 413 & .010 \\
Learning resources & -.308 & 413 & .758 \\
Writing reports and researches & -2.513 & 413 & .012 \\
Tests & .111 & 413 & .912 \\
Grand mean & -.259 & 413 & .796 \\
\hline
\end{tabular}




\section{Discussion}

The results of the study indicated that the average of possessing SS by TTU students was mid which points out the necessity for providing students with SS that are needed for university study. These skills enable students to be proficient in required instructional outcomes which ultimately improve their abilities, achievement, and make them more self- confident which reinforce the students' academic self-concept, which leads to improving achievement and learning.

The result also showed that the mean of male students for SS domains was higher than female students, but this difference does not show any statistical significance except in the domain of study management. This could be due to the fact that female students are always busy with home works helping their mothers and other members of the family; whereas male students do not share with home works.

The results indicated that male students of humanities faculties got higher average in means of the skills of writing repots and researches, and learning resources domains and this could be logical since the students of scientific faculties adopt one textbook for each subject; whereas, the students humanities faculties need more than one resource and reference for each subject. In addition to that, the students of scientific faculties in general, deal with numbers and formula; whereas the students of humanities need to write reports and researches.

The scientific faculties means were higher than humanities faculties in the domains of test, linguistic, and study management, but there is no statistical significance except in linguistic domain and this could be due to the nature of the subjects.

The results of the study meet with Seif (2001) regarding the importance of reading strategies for students, Jang, and Kim (2004), Burcak, Levent, and Kaan (2015) the necessity for managing time for study. The results disagreed with Shawana, Shaukat, Iqbal, and Sobia (2012) regarding study management which indicated in this study that male students are better than female students.

\section{Conclusion}

This study aimed to identify the degree of possessing SS by TTU students and the effect of some factors on them. It is indicated that the students are in need for these skills in order to be more effective in their learning and to increase their motivation and achievement. This could be implemented through adopting the course of SS as a compulsory course in the university. In addition to that, students who join a university should study these skills. In addition to that, students of secondary stage at schools should be trained on SS in order to be ready for joining higher education.

\section{Recommendations}

1. The curricula designers should take into account the necessity of including SS in school syllabuses from the early stages of school.

2. The course of SS should be taught for new students in universities from the first semester and it must be compulsory course.

\section{Abbreviations \\ TTU: Tafila Technical University. \\ SS: study skills. \\ SSD: study skills domain. \\ SDs: standard deviations.}

\section{References}

Alipuor, B. (1997). Study condition. Tehran: Deklamegaran.

Burcak, C., Levent, I., \& Kaan, E. (2015). Investigation of Time Management Skills of College Students who Play Sports and Do not Play Sports. Journal of Physical Education and Sport Science Movement and Health, 15(2), 602-609.

Gourlay, L. (2009). Threshold practices: Becoming a student through academic literacies. London Review of Education, 7(2), 181-192. https://doi.org/10.1080/14748460903003626

Jang, S., \& Kim, N. (2004). Transition from high school to higher education and work in Korea, from the 
competency based education perspective. International Journal of Educational Development, 24(6), 691-699. https://doi.org/10.1016/j.ijedudev.2004.04.002

Jansen E. P.W.A., \& Suhre C. J.M. (2010). The effect of secondary school study skills preparation on first year university achievement. Educational Studies, 36(5), 569-580. https://doi.org/10.1080/03055691003729070

Robbins, S., Lauver, K., Huy, L., Davis, D., Langley, R., \& Carlstrom, A. (2004). Do psychosocial and study skill factors predict college outcomes? A meta-analysis, 130(6), 261-288.

Seif, A. (2001). Training psychology. Tehran, Agah.

Shawana, F., Shaukat, H., Iqbal, M., \& Sobia, M. (2012). The role of Study Skills in Academic Achievement; A closer Focus on Gender. Pakistan Journal of Psychological Research, 27(1), 37-51.

Siahi, E., \& Maiyo, J. ( 2015). The Relationship between Study Habits and Academic Achievement of Students. International Journal of Educational Administration and Policy, 7(7), 134-141. https://doi.org/10.5897/IJEAPS2015.0404

Smith, C., \& Bath, D. (2006). The role of the learning community in the development of discipline knowledge and generic graduate outcomes. Higher Education, 51(4), 259-86. https://doi.org/10.1007/s10734-004-6389-2 